\title{
Ambiguous Genitalia Associated with an Extremely Rare Syndrome: A Case Report of XLAG Syndrome and Review of the Literature
}

\author{
Brijnandan GUPTA ${ }^{\text {, }}$ Prashant RAMTEKE' ${ }^{1}$ V K PAUL ${ }^{2}$, Tarun KUMAR' ${ }^{1}$, Prasenjit DAS ${ }^{1}$
}

Department of 'Pathology and 'Pediatrics, All India Institute of Medical Science, NEW DELHI, INDIA

\begin{abstract}
X-linked lissencephaly, absent corpus callosum, and epilepsy of neonatal onset with ambiguous genitalia comprises the XLAG syndrome and only 15 cases have been reported in literature. Due to its rarity, the exact clinical course and outcome are not known. Exact associations of this disease are also elusive. Hereby we are reporting this extremely rare entity and we searched the English literature extensively to get consolidated knowledge regarding this entity that would help the readers. Pre-natal radiological work-up can detect these malformations, which should be followed by medical termination, counseling and karyotyping. Till date the longest survival noted was 4 years only.
\end{abstract}

Key Words: Lissencephaly, Corpus callosum, Ambiguous genitalia, Epilepsy, Syndrome

\section{INTRODUCTION}

The syndrome of X-linked lissencephaly, absent corpus callosum, epilepsy of neonatal onset with ambiguous genitalia (XLAG syndrome) was first described by Dobyns et al. in 1999, who reported a lissencephaly with a posteriorto-anterior gradient, i.e. a posterior agyria and anterior pachygyria (1). This rare genetic disease occurs due to mutation of the ARX homeobox gene (Xp 22.13). This gene is situated around the ventricles, neocortex, hippocampus and can also be seen in the pancreas and testes (2). Lissencephaly in this syndrome results from abnormal neuronal migration (3). Small, dysplastic basal ganglia with ventricular cysts have been described in association with this syndrome (4). Till date only 15 cases have been reported in published English literature (1, 4-10). Herein we report one such extremely rare case we encountered during autopsy.

\section{CASE REPORT}

A preterm neonate, appropriate for date, was born by spontaneous vaginal delivery to a 20 -year-old primigravida mother at $35+3$ weeks of gestation. No history of consanguineous marriage was present. The baby did not cry after birth and was born limp and blue with APGAR Score 5 and 8 at 1 minute and 5 minutes, respectively. The birth weight of the neonate was 1882 grams and occipitofrontal circumference $(\mathrm{OFC})$ was $32 \mathrm{~cm}$. On examination, the baby had ambiguous genitalia with non-palpable testes

(Turk Patoloji Derg 2019, 35:162-165)

Received : 05.10.2016 Accepted : 30.01.2017 in the external genitalia. The baby had a first episode of convulsion within half an hour of birth with facial twitching requiring phenobarbitone followed by multiple episodes of convulsions. USG brain on day 1 showed absent corpus callosum with the underdeveloped gyri at the cortical surface (lissencephaly). Chest X-ray showed bilateral clear lungs. X-ray abdomen showed dilated bowel loops. The baby had recurrent episodes of apnoea from 36 hours, requiring initiation of nasal Intermittent Mandatory Ventilation (IMV). The blood pressure, blood glucose level, sodium and calcium levels were within normal limits. Congenital adrenal hyperplasia was ruled out on the basis of the result of biochemical examination. On the third day, the baby had multiple episodes of apnoea requiring bag and mask ventilation with the development of metabolic acidosis. The baby died on the fourth day of life due to respiratory failure and central nervous system malformation. A complete autopsy was performed. The blood sample was also sent for karyotyping but this could not be accomplished due to cell degeneration.

\section{Autopsy Findings}

Externally, ambiguous genitalia (Figure 1A) and low set ears were noticeable. Ambiguous genitalia in the index case was diagnosed as evidenced by the presence of microphallus, hypospadias, bifid scrotum and bilaterally impalpable gonads. No other external congenital malformation was seen.

Correspondence: Prasenjit DAS

All India Institute of Medical Science,

Department of Pathology, NEW DELHI, INDIA

E-mail: prasenaiims@gmail.com Phone: +91987389 8110 
The testes were located intra-abdominally (Figure 1B). The corpus callosum was completely absent (Figure 1C). All other organs in thoracic and intra-abdominal cavity were in their normal anatomical position. Cortical thickness was increased (8-9 mm) (Figure 1D). Testes were confirmed histologically (Figure 2A,B). All other organs were histologically appropriate for the developmental age. No ovary was identified microscopically. A final diagnosis of X-linked lissencephaly, absent corpus callosum with ambiguous genitalia (XLAG syndrome) was therefore offered.

\section{DISCUSSION}

Gestational ultrasound and MRI are often diagnostic for the XLAG syndrome. The MRI findings are agyria with an increased thickness of the cerebral cortex, with three abnormal layers, including gray and white matters (6-7 $\mathrm{mm}$ ) and complete agenesis of the corpus callosum. In comparison to the XLAG syndrome (cortex consists of three layers), in X-linked isolated lissencephaly sequence (XLIS) the cortex consists of four layers and the white matter is thinned out. MRI brain of asymptomatic mothers of affected babies may demonstrate partial or complete absence of corpus callosum (5).

In our case, the corpus callosum was completely absent and the cerebral cortex was abnormally thick $(8-9 \mathrm{~mm})$ with partial loss of sulci in both the anterior and posterior cortex. There were also ambiguous genitalia, low set ears, patent ductus arteriosus, foramen ovale and intra-abdominal testes. Testes were confirmed histologically. A few authors have described hypothalamic dysfunction with deficient control of body temperature $(1,5)$, but body temperature control was normal in our patient and no hypothalamic dysfunction was noted (Table I). Absent corpus callosum
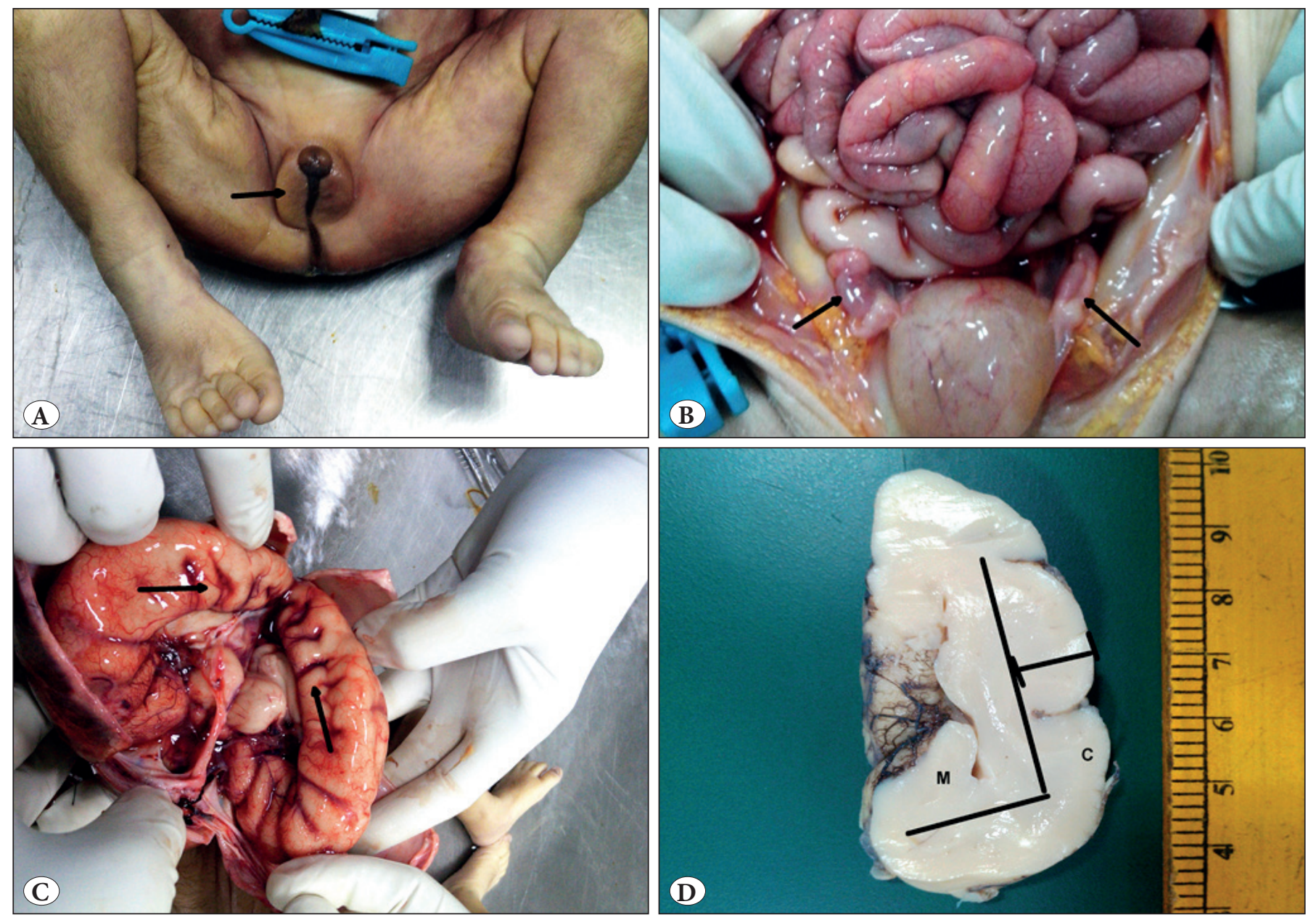

Figure 1: A) Gross photograph show a fetus, where the abdomen was opened by a midline thoraco-abdominal incision showing ambiguous external genitalia (arrow). B) Intra-abdominal bilateral testes (arrows). C) Brain examination showed absence of corpus callosum (arrows). D) A coronal slice of the brain show increased cortical thickness and under developed sulci and gyri. The distinction between cortex $(\mathrm{C})$ and white matter $(\mathrm{M})$ has been represented by a schematic line. 

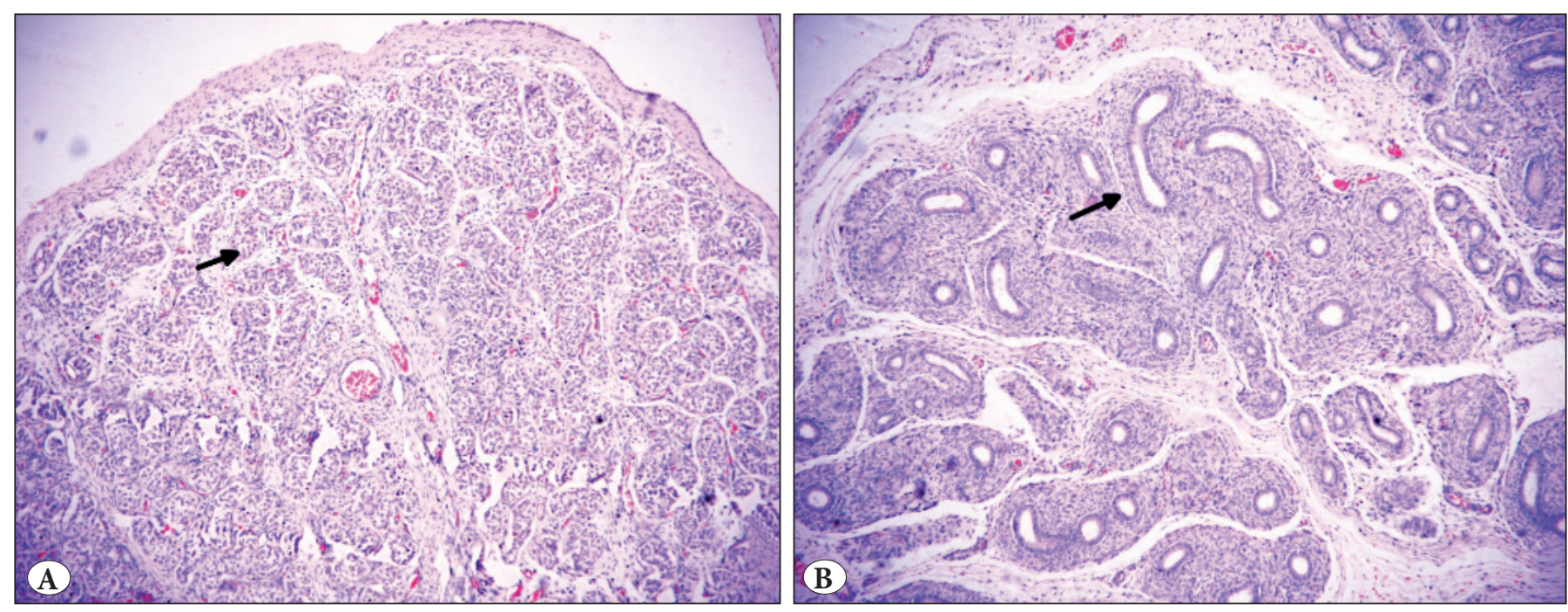

Figure 2: A) Seminiferous tubules (arrow) with Sertoli cells (H\&E; x40). B) Epididymis (arrow) was also identified (H\&E; x100).

Table I: Cases of XLAG syndrome reported in the literature

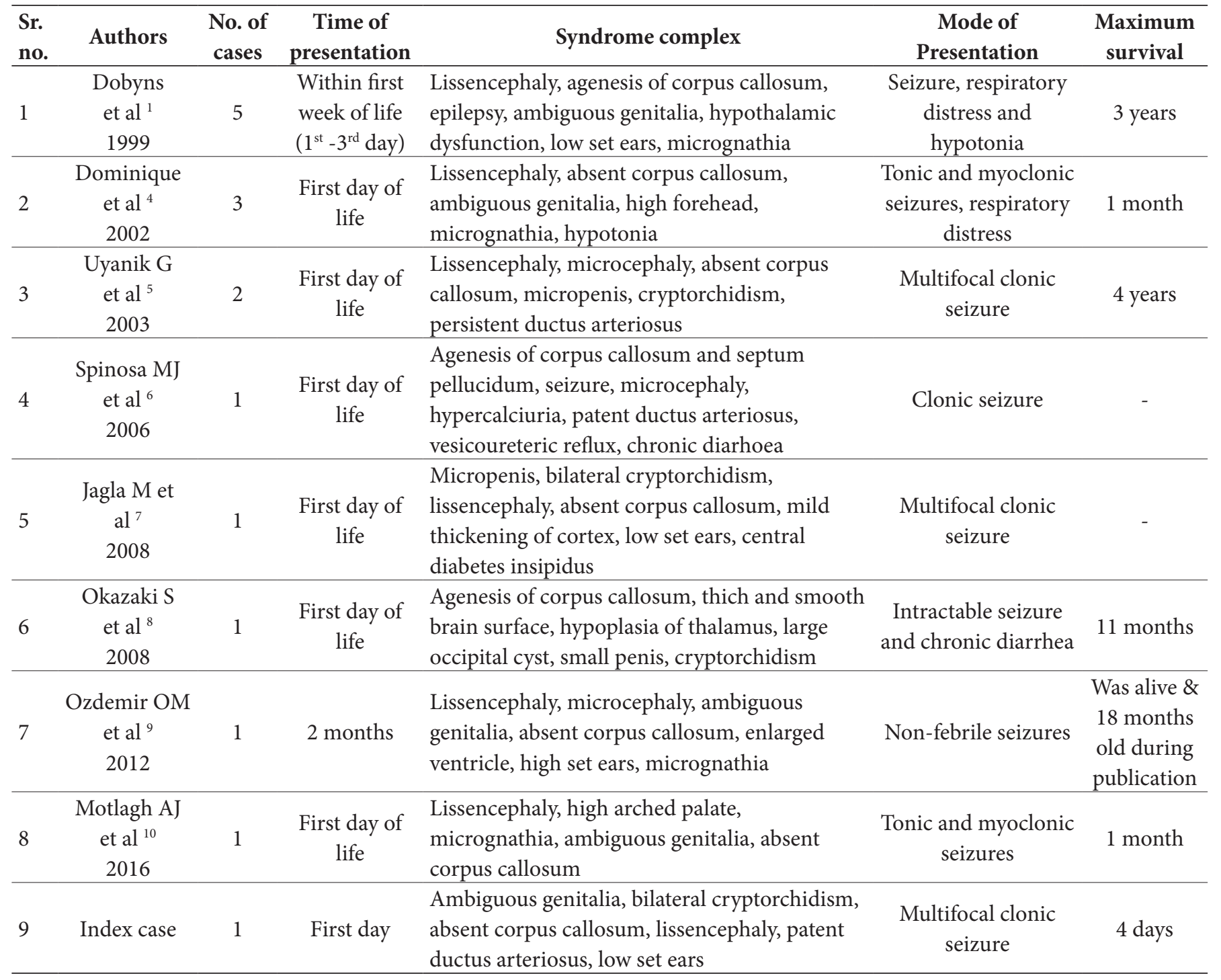


can be associated with abnormalities such as agenesis of vermis cerebelli, hydrocephalus, polymicrogyria, cerebellar hypoplasia, and lissencephaly. Many cases of absent corpus callosum have syndromic association with Fetal akinesia syndrome, XLAG syndrome, Dandy-Walker Malformation, Trisomy 13,18,21 and Thanatophoric dysplasia $(11,12)$.

Seizures occur frequently in this syndrome. Tonic, multifocal myoclonic and generalized tonic-clonic seizures have been reported $(4,5)$. Uyanik et al. have described a case with marked fetal movements suggestive of prenatal seizure (5). In the index case, the baby had episodes of multifocal clonic seizure with facial twitching which started within half an hour of birth and increased in intensity gradually. Overall prognosis in XLAG syndrome is poor with a maximum reported survival of 4 years (Table I). Though the sample was sent for karyotyping, satisfactory test results could not be obtained due to poor quality of the sample. However, the clinical and autopsy findings were enough to help us reach a diagnosis.

Antenatal history of mother revealed absent folic acid intake in our case. The association of absent folic acid intake in the mother and occurrence of this syndrome has not been previously reported. There is therefore a need for further investigation to know whether there is any relationship between absent folic acid intake and the occurrence of this disorder with developmental malformation of central nervous system.

In conclusion, the XLAG syndrome is an extremely rare congenital malformation of male newborns with ambiguous genitalia and loss of corpus callosum with hypothalamic dysfunction. This needs to be identified during prenatal radiological work up as the longest reported survival is only 4 years after birth. Proper counseling of the couple with karyotyping and genetic tests is imperative to decide upon future pregnancy.

\section{REFERENCES}

1. Dobyns WB, Berry-Kravis E, Havernick NJ, Holden KR, Viskochil D. X-linked lissencephaly with absent corpus callosum and ambiguous genitalia. Am J Med Genet. 1999;86:331-7.

2. Miura H, Yanazawa M, Kato K, Kitamura K. Expression of a novel aristaless related homeobox gene 'Arx' in the vertebrate telencephalon, diencephalon and floor plate. Mech Dev. 1997;65:99-109.

3. Neuronal migration disorders and cortical dysplasia. In: Norman MG, McGillivray BC, Kalousek DK, Hill A, Poskitt KJ, editors. Congenital malformations of the brain. Pathological, embryological, clinical, radiological and genetic aspects. Oxford: Oxford University Press;1995:223-77.

4. Bonneau D, Toutain A, Laquerrière A, Marret S, Saugier-Veber P, Barthez MA, Radi S, Biran-Mucignat V, Rodriguez D, Gélot A. X-linked lissencephaly with absent corpus callosum and ambiguous genitalia (XLAG): Clinical, magnetic resonance imaging, and neuropathological findings. Ann Neurol. 2002;51:340-9.

5. Uyanik G, Aigner L, Martin P, Gross C, Neumann D, MarschnerSchäfer H, Hehr U, Winkler J. ARX mutations in X-linked lissencephaly with abnormal genitalia. Neurology. 2003;61:232-5.

6. Spinosa MJ, Liberalesso PB, Vieira SC, Olmos AS, Löhr A Jr. Lissencephaly, abnormal genitalia and refractory epilepsy: Case report of XLAG syndrome. Arq Neuropsiquiatr. 2006;64:1023-6.

7. Jagła M, Kruczek P, Kwinta P. Association between X-linked lissencephaly with ambiguous genitalia syndrome and lenticulostriate vasculopathy in neonate. J Clin Ultrasound. 2008;36:387-90

8. Okazaki S, Ohsawa M, Kuki I, Kawawaki H, Koriyama T, Ri S, Ichiba H, Hai E, Inoue T, Nakamura H, Goto Y, Tomiwa K, Yamano T, Kitamura K, Itoh M. Aristaless-related homeobox gene disruption leads to abnormal distribution of GABAergic interneurons in human neocortex: Evidence based on a case of $\mathrm{X}$-linked lissencephaly with abnormal genitalia (XLAG). Acta Neuropathol. 2008;116:453-62.

9. Özdemir ÖM, Cağlar M, Koçyiğit A, Dündar NO, Sangün Ö, Dündar B. Primary hypogonadism in a case with XLAG syndrome. J Pediatr Endocrinol Metab. 2012;25:1161-3.

10. Motlagh AJ, Zahedpasha Y, Ahmadpourkacho M. X-Linked Lissencephaly with absent corpus callosum and ambiguous genitalia: A case report. Iranian Journal of Neonatology 2016;7:75-9.

11. Berg MJ, Schifitto G, Powers JM, Martinez-Capolino C, Fong CT, Myers GJ, Epstein LG, Walsh CA. X-linked female band heterotopia-male lissencephaly syndrome. Neurology. 1998;50:1143-6.

12. Kitova TT, Kitov B, Milkov D, Gaigi S. Postnatally diagnosed agenesis of corpus callosum in fetuses. Fetal Pediatr Pathol. 2014;33:239-43. 